\title{
MythBusters
}

\section{Myth: Refugee Health Care Cuts Will Decrease Overall Health Care Costs}

\author{
Austin Zygmunt \\ Dalhousie Medicine, Class of 2016
}

Canada has a long-standing history as a safe-haven for refugees, accepting, on average, 25,000 to 30,000 annually. ${ }^{1-4}$ The United Nations High Commissioner for Refugees defines a refugee as "someone who is unable or unwilling to return to their country of origin owing to a well-founded fear of being persecuted for reasons of race, religion, nationality, membership of a particular social group, or political opinion." ${ }^{5}$

In 1957, the Interim Federal Health Program (IFHP) was created to provide basic health care, dental care, vision care, prescription drug, and medical device coverage to refugees not qualifying for provincial or territorial health insurance plans. ${ }^{4,6}$ On June 30, 2012 the federal government made cuts to the IFHP, eliminating all health care for refugees except for urgent care and care for transmissible diseases that pose a risk to public health (e.g., tuberculosis). ${ }^{4,7}$ This decision was made, in part, to save money for taxpayers, with government reports estimating savings at $\$ 100$ million over five years. ${ }^{8}$ Overall, expenses for the IFHP were $\$ 85$ million per year, representing a fraction of total health care expenditure in Canada at $0.04 \% .^{9}$ In addition, the annual cost of the IFHP per refugee was $\$ 660$, roughly $10 \%$ of the average $\$ 6141$ cost per Canadian citizen., ${ }^{4,10}$ Although government-sponsored refugees are excluded from these cuts, the majority of refugees who are privately sponsored or make their claim after arriving in Canada are affected. ${ }^{4}$

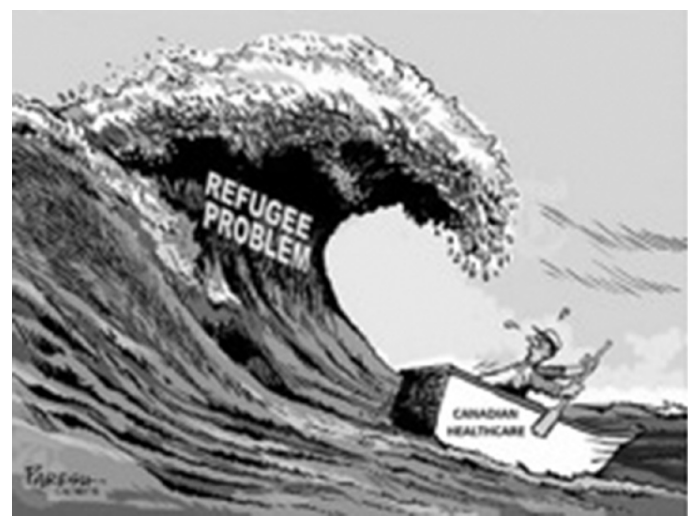

\section{Refugees Have Poorer Health}

Refugees are at high risk of communicable and chronic diseases due to their exposure to harmful living conditions in their home countries such as violence, torture, trauma, and starvation. ${ }^{3,7,11}$ Many refugees come to Canada with significant health care burden, never having experienced first world health care in their home country. ${ }^{12}$ Refugee health care burden is dependent on a variety of factors from their past including: exposure from vectors of disease (e.g., mosquitoes transmitting malaria), trauma from war (e.g., post-traumatic stress disorder), poor living conditions (e.g., malnutrition, poor sanitation, no access to water, crowded camps), inadequate social determinants of health (low income and education), and limited or no access to preventive care (e.g., lack of immunizations and screening programs, language and cultural barriers to care). ${ }^{3}$

Refugees have statistically significantly higher rates of treatable and preventable diseases compared to the general Canadian population. ${ }^{1-3,13}$ Refugees are susceptible to vaccine preventable diseases because of under-immunization in their home country, waning immunity from previous immunizations, or both. ${ }^{3}$ The most common vaccine-preventable illnesses afflicting refugees are tetanus, measles, mumps, rubella, varicella, and hepatitis $B^{3,14}$ Many refugees also struggle with mental health conditions such as post-traumatic stress disorder, depression and anxiety as well as chronic conditions such as type II diabetes, iron deficiency anemia, dental disease, and poor vision health. ${ }^{3,14}$ Other common illnesses include hepatitis $C$, tuberculosis, HIV/AIDS, malaria, and complications from intestinal parasites. ${ }^{14}$ Female refugees may also require contraceptive medications, vaccination against human papillomavirus, and screening for cervical cancer. $^{3}$

\section{Short Term Gain for Long Term Pain}

Initial short-term savings may result from cuts to the IFHP, however, long-term costs may increase as refugee health care is shifted from preventive and primary care to emergency and urgent care. ${ }^{7,15}$ Those that do not access primary care for their health conditions typically delay seeking medical treatment, do not use 
preventive health care services, and are at greater risk of complications from their illnesses. ${ }^{16}$ They also tend to enter the health care system sicker, later, and stay for a more prolonged period of time, putting an increased financial burden on other parts of the health care system such as an excess number of emergency department visits. ${ }^{16-18}$ Refugees that are unable to pay for basic health care may get sicker and suffer from complications of unmet health care needs, forcing them to use more costly emergency and urgent care. ${ }^{4,18}$ Confusion among health providers on what services refugees remain eligible for has led to refugees being turned away from emergency departments. ${ }^{4}$

The prevalence of physical and mental health conditions may increase for refugees due to inadequate monitoring and undiagnosed conditions. ${ }^{18}$ Refugees may also suffer from higher mortality rates from their medical conditions compared to the general population due to a greater degree of undetected and untreated cases. ${ }^{3}$ Contagious and deadly conditions that remain undiagnosed until they have already posed a public health concern may also increase financial burden on taxpayers. ${ }^{18}$

Refugees who are not treated for their physical and mental health conditions may have worse health outcomes later in life. ${ }^{7}$ This is concerning for refugees that eventually become Canadian citizens and become eligible for their respective provincial or territorial health insurance. Once Canadian citizens, previous communicable and chronic health conditions that were not diagnosed or treated may result in long-term and costly chronic care. ${ }^{7}$

\section{Conclusion}

Many refugees enter Canada suffering from a variety of communicable and chronic diseases, mental health problems, and/or women's health issues. Eliminating or restricting refugees' access to primary and preventive health care may lead them to delay seeking timely treatment until their health conditions require urgent medical attention. Although cuts to the Interim Federal Health Program may save costs initially, as refugee care is shifted from preventive and primary care to emergency care, there may be an increased financial burden in excess of the anticipated savings.

\section{References}

1. Kiss V, Pim C, Hemmelgarn BR, Quan H. Building knowledge about health services utilization by refugees. J Immigr Minor Health 2011;15:57-67.

2. Pottie K, Janakiram P, Topp P, McCarthy A. Prevalence of selected preventable and treatable diseases among governmentassisted refugees: Implications for primary care providers. Can
Fam Physician 2007;53:1928-1934.

3. Pottie K, Greenaway C, Feightner J, Welch V, Swinkels H, Rashid $\mathrm{N}$, et al. Evidence-based clinical guidelines for immigrants and refugees. CMAJ 2011;183:824-925.

4. Arya N, McMurray J, Rashid M. Enter at your own risk: Government changes to comprehensive care for newly arrived canadian refugees. CMAJ 2012;184:1875-1876.

5. United Nations High Commissioner for Refugees. 1951 geneva convention relating to the status of refugees http://www.unhcr. org/3b66c2aa10.html. Updated 2010. Accessed Nov 12, 2012.

6. Service Canada. Interim federal health program. http://www. servicecanada.gc.ca/eng/goc/interim_health.shtml. Updated 2012. Accessed Nov 12, 2012.

7. UofT Psychiatry Position Statement. Interim federal health program cuts and bill C31. http://www.utpsychiatry.ca/bill-c31uoft-psychiatry-position-statement/. Updated 2012. Accessed Nov 12, 2012.

8. Citizenship and Immigration Canada. Reform of the interim federal health program ensures fairness, protects public health and safety. www.cic.gc.ca/english/department/media/ releases/2012/2012-04-25.asp. Updated 2012. Accessed January 7, 2013.

9. Stall N. Refugee health reforms assailed. CMAJ 2012;184:511512.

10. Canadian Council for Refugees. Government information on refugee healthcare changes is misleading and the consequences may be fatal to many. http://ccrweb.ca/en/bulletin/12/05/03. Updated 2012. Accessed January 7, 2013.

11. Picard A. Why cutting health care for asylum-seekers makes no sense. The Globe and Mail. May 14, 2012. Available from: http://www.theglobeandmail.com/life/health-and-fitness/ why-cutting-health-care-for-asylum-seekers-makes-no-sense/ article4178642/.

12. Lett D. Compassion serves a political purpose - manitoba tweaks feds on refugee health. Winnipeg Free Press. September 15, 2012. Available from: http://www.winnipegfreepress.com/ local/compassion-serves-a-political-purpose-169880896.html.

13. Keyes EF. Mental health status in refugees: An integrative review of current research. Issues Ment Health Nurs 2000;21:397-410.

14. Fowler N. Providing primary health care to immigrants and refugees: The north hamilton experience. CMAJ 1998;159:388391.

15. McLaren J. Stop cuts to refugee health. Rabble.ca. May 11, 2012. Available from: http://rabble.ca/blogs/bloggers/jesse/2012/05/ stop-cuts-refugee-health.

16. Sanmartin C, Ross N. Experiencing difficulties accessing firstcontact health services in canada. Healthc Policy 2006;1:103119.

17. Oster A, Bindman AB. Emergency department visits for ambulatory care sensitive conditions: Insights into preventable hospitalizations. Med Care 2003;41:198-207.

18. Dosani N, Ritika G. Ten reasons why the refugee health care cuts are a bad idea. http://healthydebate.ca/opinions/tenreasons-why-the-refugee-health-care-cuts-are-a-bad-idea. Updated 2012. Accessed Nov 12, 2012. 